\title{
Machinalibilty of Ti-6Al-4V Under Dry and Near Dry Condition Using Carbide Tools
}

\author{
Ahmad Yasir M.S ${ }^{1,}$, Che Hassan C.H ${ }^{2}$, Jaharah A.G ${ }^{2}$, Nagi H.E ${ }^{2}$, Yanuar B ${ }^{2}$ and Gusri A.I ${ }^{2}$ \\ ${ }^{1}$ Department of Mechanical and Manufacturing, University Kuala Lumpur-Malaysia France Institute, Bangi. \\ ${ }^{2}$ Department of Mechanical and Material, Malaysia National University, Bangi.
}

\begin{abstract}
The effectiveness of the usage of coolant in high speed machining of highly reactive material like titanium and its alloys is still far away uncertain. For this reason, it is wiser to study the effectiveness of Minimum Quantity of Lubricant (MQL) under transient cutting speed before advancing to high speed machining. This paper discusses the effect of MQL on the machinability of Ti-6Al-4V using Physical Vapor Disposition (PVD) coated cemented carbide tools. The machinability studied parameters were the generated cutting force and the tool life. The performance of PVD coated cemented carbide tool was investigated at various cutting condition under dry and near dry (or MQL) machining. For near dry machining, two levels of coolant flow rate of 50 and $100 \mathrm{~mL} / \mathrm{H}$ were investigated. The effectiveness of mist coolant was tested at three different levels of cutting speed, 120,135 and $150 \mathrm{~m} / \mathrm{min}$. Application of mist coolant is more effective at cutting speed of $135 \mathrm{~m} / \mathrm{min}$. At this speed longer tool life was obtained when more coolant was applied. The effect of the cutting speed and coolant flow rate on the surface roughness is not significant. Surface roughness is more sensitive to the feed rate and the depth of cut. No significant effect of MQL on cutting force at early stage of machining was observed. MQL seems to be more effective when tools start to wear out, where greater contact area between tool and work piece occurs to give better lubrication effect.
\end{abstract}

Keywords: PVD cemented carbide, dry machining, near dry machining, Titanium alloy, tool life, surface roughness, micro hardness, metallurgical alteration.

\section{INTRODUCTION}

Titanium and its alloys are widely used in aerospace industries due to attractive characteristics of the material, namely high strength-weight ratio at elevated temperature, exceptional corrosion resistance, and longer service life. However, these materials have been classified as difficult-tomachine material because of their high temperature strength, low thermal conductivity and chemical reactivity and relatively low modulus of elasticity [1]. Furthermore these materials can catch fire at temperature $610^{\circ} \mathrm{C}$ and the only material can burn in pure nitrogen [2].

In machining process, most of the mechanical energy used to remove material becomes heat. This heat generates high temperature in the cutting region. The higher the cutting speed, the faster the heat generation and higher temperature resulted. The new challenge in machining is to use high cutting speed in order to increase the productivity. This is the main reason for rapid tool wear. For titanium and its alloy, this problem is more severe due to there low thermal conductivity. $80 \%$ of the heat generated in the cutting region goes to the cutting tool [3].

Conventional method used to reduce this tool wear is by using cutting fluid. This cutting fluid acts as lubricant and

\footnotetext{
*Address correspondence to this author at the Department of Mechanical and Manufacturing, University Kuala Lumpur-Malaysia France Institute, Bangi: Tel: 603-89262022; Fax: 603-89258845;

E-mail: yasir@mfi.unikl.edu.my
}

coolant as well during the machining process. Usage of cutting fluid can increase the cutting speed up to $30 \%$ without affecting the tool life. However the usage of cutting fluid has negative effect to the economy, environment and health. Total cost as concerning cutting fluid is about $17 \%$ of the total production cost compared to the cost for cutting tool that is only $4 \%$ [4]. It shows that using cutting fluid is no longer economically sound when most of the cutting tool can be produced at lower cost.

Inappropriate handling of used cutting fluid may cause damage to the environment. This cutting fluid need to be threatened properly, based on rigid rules of environment protection before disposal. In other hand, machine operators are exposed to the negative effect of cutting fluid such as by skin and lung problems [5].

However, total elimination of cutting fluid seems to be not promising due the unsatisfactory tool life and poor surface finish [6]. This rapid tool wear not only gives higher surface roughness value, but also higher micro hardness and major microstructure alteration [7].

Advanced development of coating material for cutting tools has contributed significant improvement in the machining process. Coating material creates additional lubricating layer between cutting tool and work material [8]. This makes coated cutting tools feasible for dry and near dry machining and high speed cutting [9]. But for machining of titanium and its alloys, the effect of coating material is far away uncertain due to the chemical reactivity of the work material. 
For aerospace application like titanium and its alloy, the quality of surface finish is very crucial in term of very high demand for performance, safety, lifetime, life cycle cost, and reliability [10]. Study of surface integrity of machined component now becomes important and essential in order to produce high quality product.

Another major problem in machining of titanium alloy is to apply High-speed machining. The advantages of highspeed machining are higher productivity, better surface finished, burr-free edges and virtually stress-free component after machining[11]. Another significant advantage of highspeed machining is that lower cutting force is applied and it can reduce heat generation and increase the life of the cutting tool. However, the need of cutting fluid for high-speed machining of titanium alloys needs to be investigated. Application of conventional cutting fluid in high speed machining is not effective, because the fluid fails to penetrate the chip-tool interface even with additional extreme pressure is applied [5]. Total elimination of cutting fluid seems to be not promising due the unsatisfactory tool life and poor surface finish especially when dealing with heat resistant material [12].

Research has showed that using extremely low amount of cutting fluid is feasible and seems to be promising to have longer tool life and better surface finish for milling operation $[9,10,12]$. This method is known as Minimum Quantity of Lubrication (MQL) and is considered as dry machining. The cutting fluid is sprayed into the cutting region in the form of mist. This mist will vaporize and left no residue. The only problem is that proper mist extractor is required to avoid the machine operator from breathing this mist.

\section{METHODOLOGY}

\subsection{Work Piece Material}

Among the titanium alloy used in aerospace industries, the Titanium alloy from alpha-beta group Ti-6Al-4V is the most widely used. This material is selected for this experiment. The composition (wt\%) and the mechanical properties of this material are shown in Tables $\mathbf{1}$ and $\mathbf{2}$ respectively.

Table 1. Composition (wt\%) of Ti-6Al-4V

\begin{tabular}{|c|c|c|c|c|c|c|c|c|}
\hline Content & $\mathbf{O}$ & $\mathbf{H}$ & $\mathbf{N}$ & $\mathbf{C}$ & $\mathbf{F e}$ & $\mathbf{V}$ & $\mathbf{A l}$ & $\mathbf{T i}$ \\
\hline \hline $\mathrm{Wt} \%$ & - & 0.005 & 0.01 & 0.05 & 0.09 & 4.40 & 6.15 & Balance \\
\hline
\end{tabular}

Table 2. Mechanical Properties of Ti-6Al-4V at Room Temperature

\begin{tabular}{|c|c|c|c|c|}
\hline $\begin{array}{c}\text { Tensile } \\
\text { strength } \\
\text { (MPa) }\end{array}$ & $\begin{array}{c}\text { Yield } \\
\text { strength } \\
\text { (MPa) }\end{array}$ & Elongation & $\begin{array}{c}\text { Modulus of } \\
\text { elasticity } \\
\text { (GPa) }\end{array}$ & $\begin{array}{c}\text { Hardness } \\
\text { (HRC) }\end{array}$ \\
\hline \hline 993 & 830 & 14 & 114 & 36 \\
\hline
\end{tabular}

\subsection{Cutting Tool Materials}

PVD coated cemented carbide was used in this experiment. This insert is mounted on a $16 \mathrm{~mm}$ diameter end-mill cutter. Only one tooth is used at each experiment. The geometry of the insert is round with diameter $10 \mathrm{~mm}$. The no- table data for the insert and the coating material are shown in Table 3, 4 and 5 respectively. Fig. (1) shows the tool together with the insert used in this experiment.

Table 3. Cutting Tool Composition

\begin{tabular}{|c|c|c|}
\hline Content & WC & Co \\
\hline \hline wt \% & 87 & 13 \\
\hline
\end{tabular}

Table 4. Physical and Mechanical Properties of Cutting Tool

\begin{tabular}{|c|c|c|c|c|}
\hline $\begin{array}{c}\text { Particle } \\
\text { Size }\end{array}$ & $\begin{array}{c}\text { Hardness } \\
\mathbf{2 5}^{\circ} \mathbf{C}\end{array}$ & Density & $\begin{array}{c}\text { Modulus } \\
\text { of Elastic- } \\
\text { ity }\end{array}$ & $\begin{array}{c}\text { Coefficient } \\
\text { of Thermal } \\
\text { Expansion }\end{array}$ \\
\hline \hline $0.8 \mu \mathrm{m}$ & $1470 \mathrm{Hv}_{10}$ & $14.5 \mathrm{~g} / \mathrm{cm}^{3}$ & $580 \mathrm{GPa}$ & $5.5 \times 10^{-6} / \mathrm{K}$ \\
\hline
\end{tabular}

Table 5. Geometry of Cutting Tool

\begin{tabular}{|c|c|c|}
\hline Cutting Rake & Axial Rake & Radial Rake \\
\hline \hline$-4^{\circ}-0^{0}$ & $+6^{\circ}$ & $-4^{\circ}-0^{\circ}$ \\
\hline
\end{tabular}

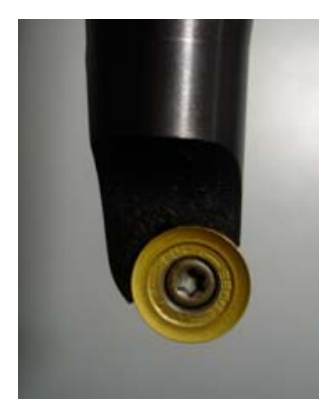

Fig. (1). Tool and insert used in this experiment.

\subsection{Cutting Fluids}

Water immiscible cutting fluid was used during this experiment. However, this coolant is miscible with solvent or mineral oil. Desired coolant flow rate was achieved by regulating the supplied air pressure and the opening of nozzle. The nominal data of this cutting fluid is shown in Table 6.

Table 6. Mechanical Properties of Cutting Fluid

\begin{tabular}{|c|c|c|c|}
\hline Specific Gravity & Viscosity & Flash Point & Pour Point \\
\hline \hline $0.874 \mathrm{~g} / \mathrm{cm}^{3}$ & $22.2 \mathrm{~mm}^{2} / \mathrm{s}$ & $178^{\circ} \mathrm{C}$ & $-30^{\circ} \mathrm{C}$ \\
DIN 51757 & DIN 51562 & ISO 2592 & ISO 3016 \\
\hline
\end{tabular}

\subsection{Machining Test}

All the machining tests were carried out on 3 -axis $\mathrm{CNC}$ milling machine. The dimensions of the Ti-6Al-4V test piece are $100 \times 100 \times 160 \mathrm{~mm}$. These test pieces were pre-machined $2 \mathrm{~mm}$ thick of each surface before the experiment in order to remove the residual stress and aging at the outer layer.

In order to measure the cutting force during machining, this work piece was mounted and fixed on 3-axis dyna- 
mometer. Fig. (2) shows the setting up for cutting force measurement.

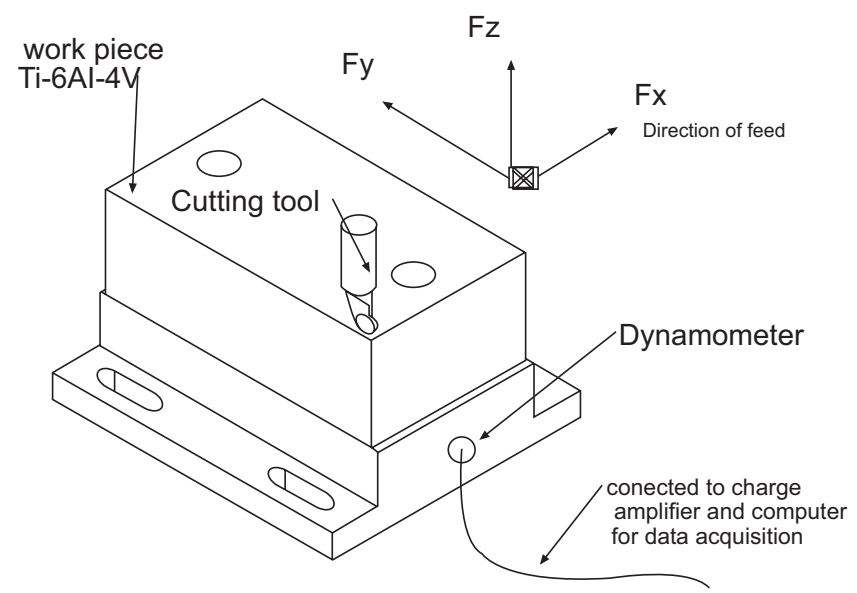

Fig. (2). Measurement of cutting force

Design of experiment was multilevel factorial design, used in this experiment. Summary of the DOE is shown in Table 7. The radial depth of cut was kept constant i.e $10 \mathrm{~mm}$. Fig. (3) shows the direction of the nozzle for the mist coolant. Type of cutting used in this experiment is climb milling.

\section{Table 7. Factors and Level for DOE}

\begin{tabular}{|c|c|c|c|}
\hline Factors / Levels & $\mathbf{1}$ & $\mathbf{2}$ & $\mathbf{3}$ \\
\hline \hline $\begin{array}{c}\text { A- Coolant flow rate, } \\
(\mathrm{mL} / \mathrm{H})\end{array}$ & 0 & 50 & 100 \\
\hline $\begin{array}{c}\text { B- Cutting speed, } \mathrm{V}_{\mathrm{c}} \\
(\mathrm{m} / \mathrm{min})\end{array}$ & 120 & 135 & 150 \\
\hline $\begin{array}{c}\text { C- Feed rate, FR } \\
(\mathrm{mm} / \text { tooth })\end{array}$ & 0.1 & 0.125 & \\
\hline $\begin{array}{c}\mathrm{D}-\mathrm{Axial} \text { Depth of cut } \\
\text { (DOC), a - mm }\end{array}$ & 2 & 2.5 & \\
\hline
\end{tabular}

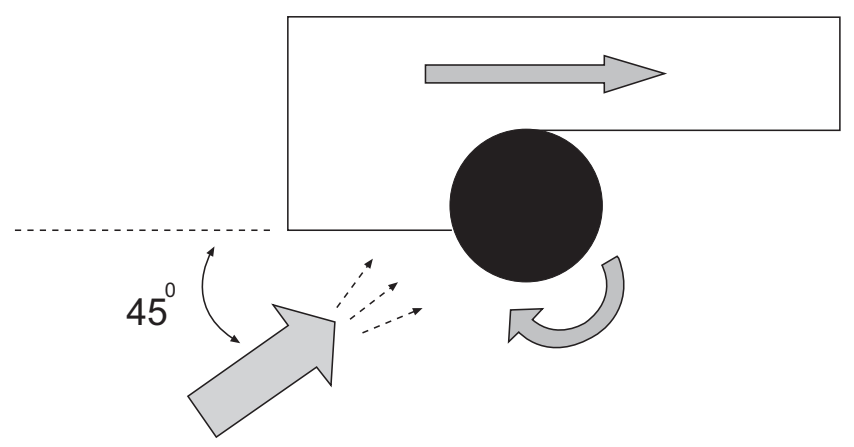

Fig. (3). Effective direction for nozzle [13].

Machining were stop at various time intervals to measure the tool wear progressively. Measurements of tool wear were stopped, when either one of these criteria was obtained:

- the flank wear reached $0.3 \mathrm{~mm}$

- catastrophic tool failure

- machining time reached 20 minutes

\section{RESULTS AND DISCUSSION}

\subsection{Tool Life}

The data for the tool life at various cutting condition are given in the histogram shown in Fig. (4). Histogram 4(a) shows the tool life obtained from this experiment in group of cutting speed. This histogram shows the strong relation between the cutting speed and tool life. Higher cutting speed results in shorter tool life. But at higher feed rate and depth of cut, effect of cutting speed is less significant. This is due to fracture failure and is more important than gradual wear when high feed rate and high depth of cut are applied. Contrary, when the histogram of tool life is plotted by group of $\mathrm{MQL}$ as shown in 4(b), there is no linear correlation between the tool life and amount of MQL applied.

Longer tool life, when higher amount of coolant is applied, only occurs at cutting of $135 \mathrm{~m} / \mathrm{min}$. At the speed of $120 \mathrm{~m} / \mathrm{min}$, dry machining gives better tool life. Shorter tool life under MQL $50 \mathrm{~mL} / \mathrm{H}$ is observed due to the chemical wear [14]. Evidence of chemical wear is shown by fast wear growth after the wear reach $0.2 \mathrm{~mm}$. The wear increase drastically when the coating material had been eliminated. The graphs for the progress wear growth are shown in Fig (5). Under MQL $100 \mathrm{~mL} / \mathrm{H}$, the effect of chemical wear is less because sufficient amount of coolant is available to give the cooling effect. Contrary, for cutting speed $150 \mathrm{~m} / \mathrm{min}$, MQL $100 \mathrm{~mL} / \mathrm{H}$ is less efficient as compared to MQL $50 \mathrm{~mL} / \mathrm{H}$. This is due to the bigger size of mist particles that can not penetrate in to the cutting zone. The penetration of this particle is hindered by the centrifugal force created by the rotating tool.

\subsection{Surface Roughness}

The data of the variation of the surface roughness with respect to the length of travel in various cutting condition are shown in Fig. (6). From the result on the surface roughness obtained, no co-relation can be retrieved between the surface roughness and the neither the cutting speed nor the coolant flow rate. This is because the surface roughness depends more on the machine tool rigidity and the geometry of the cutting tool [15]. Beside of that, cutting parameters such as feed rate gives significant effect on surface roughness. This experiment had proved that, higher feed rate results in higher value of surface roughness.

Low value of surface roughness obtained during this experiment is due the geometry of the cutting tool used. Round shape insert can be considered as large nose radius. Higher the nose radius, lower the value of the surface roughness. The vibration or chatter occurred during the machining process can give significant impact on the surface finish. Selection of cutting parameters is very crucial in order to avoid chatter.

\subsection{Cutting Force}

Fig. (7) shows the histograms of the average value of cutting force obtained at the beginning of the machining for various cutting conditions. At this stage, the cutting tool still sharp. From this histogram, we can conclude that, there is strong correlation between the cutting force and depth of cut. Moderate correlation exists between cutting force and feed rate. Higher the feed rate and the depth of cut result higher 


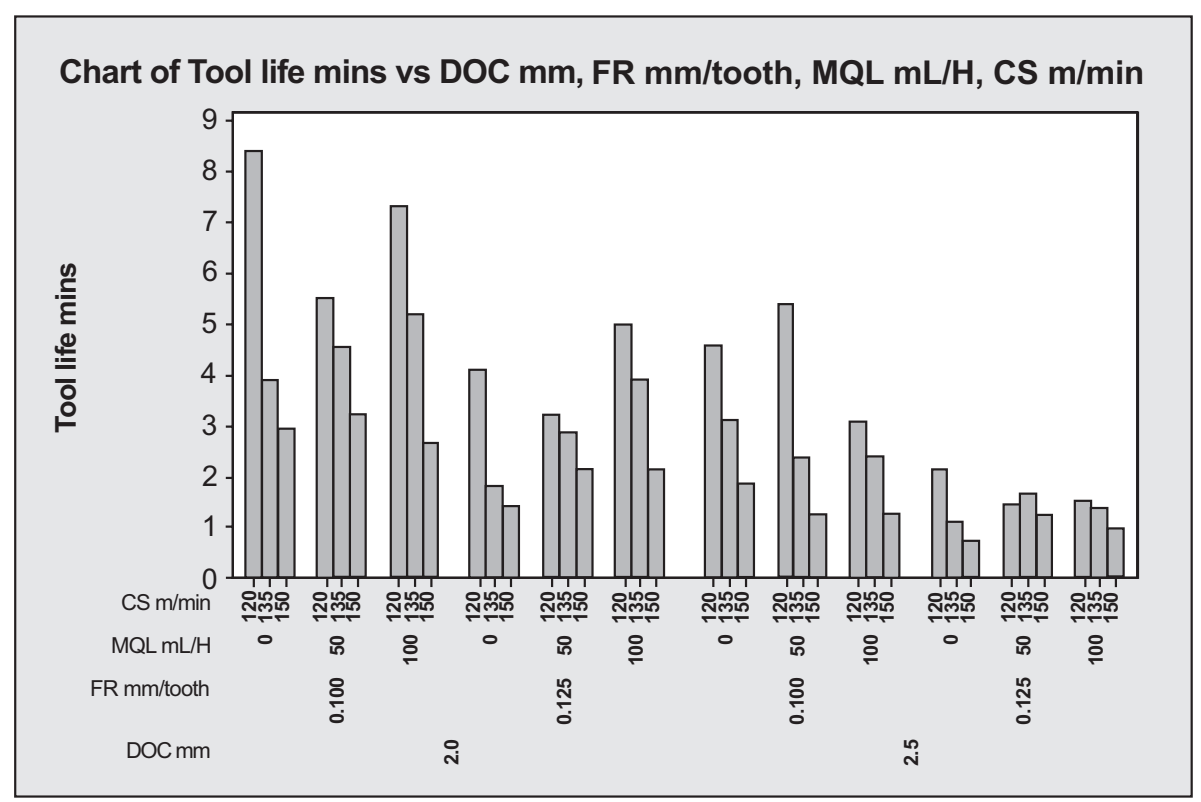

(a)

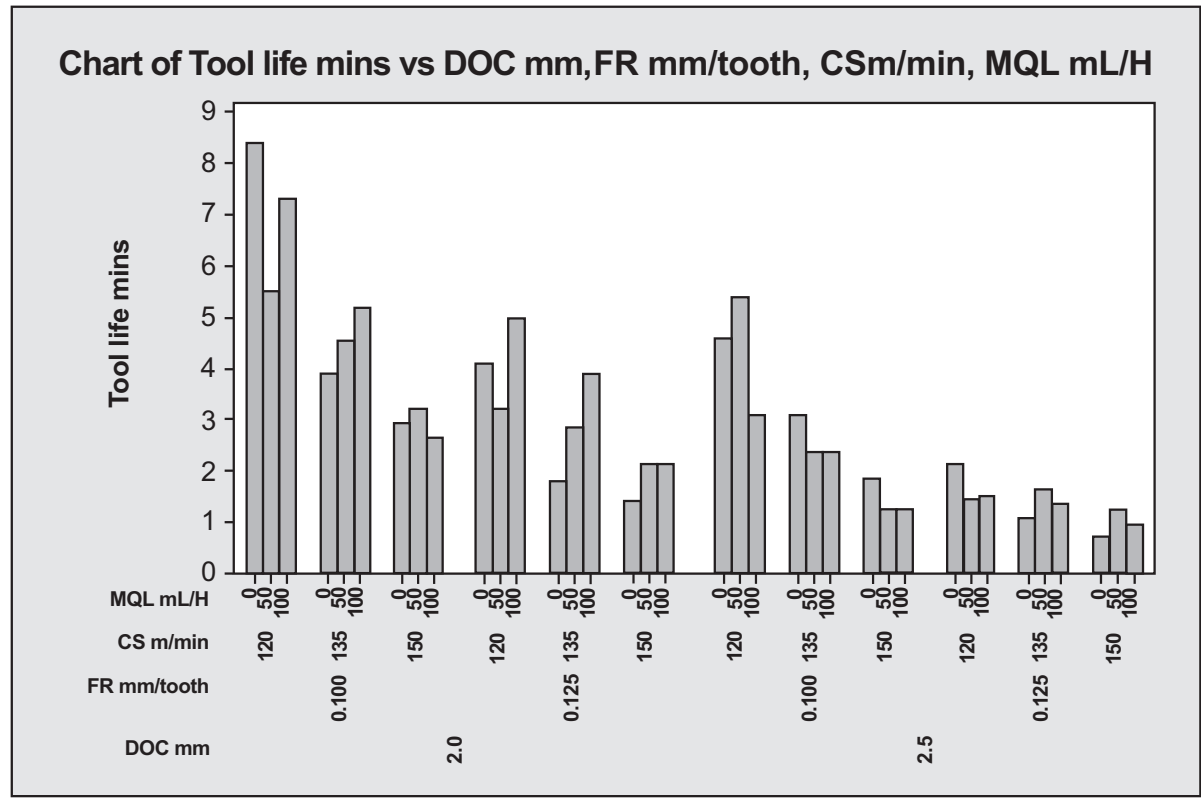

(b)

Fig. (4). (a) Histogram of tool life vs cutting speed, coolant and feed rate (b) Histogram of tool life vs MQL, cutting speed, feed rate and depth of cut.

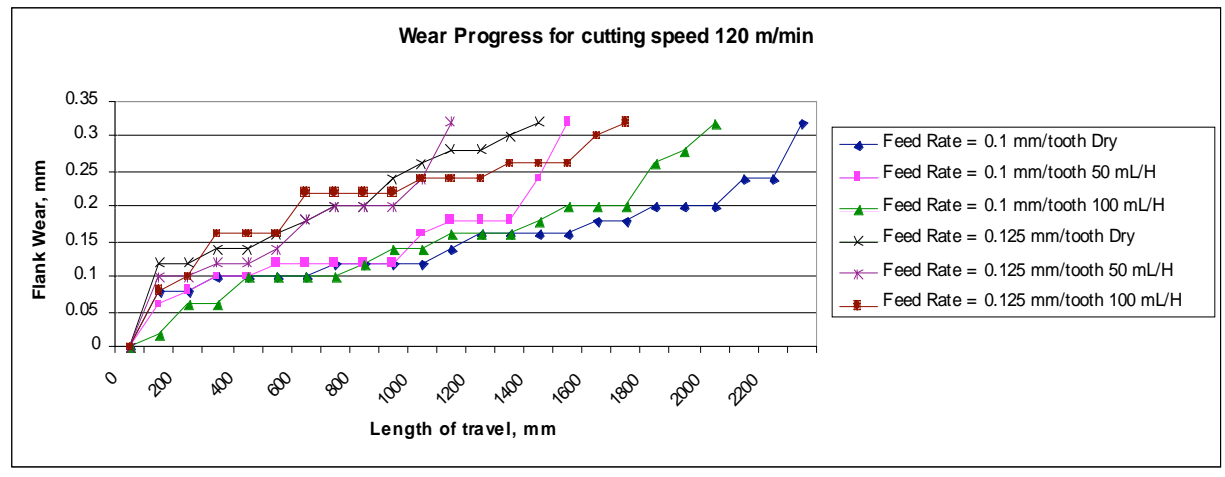


Fig. (5). contd....

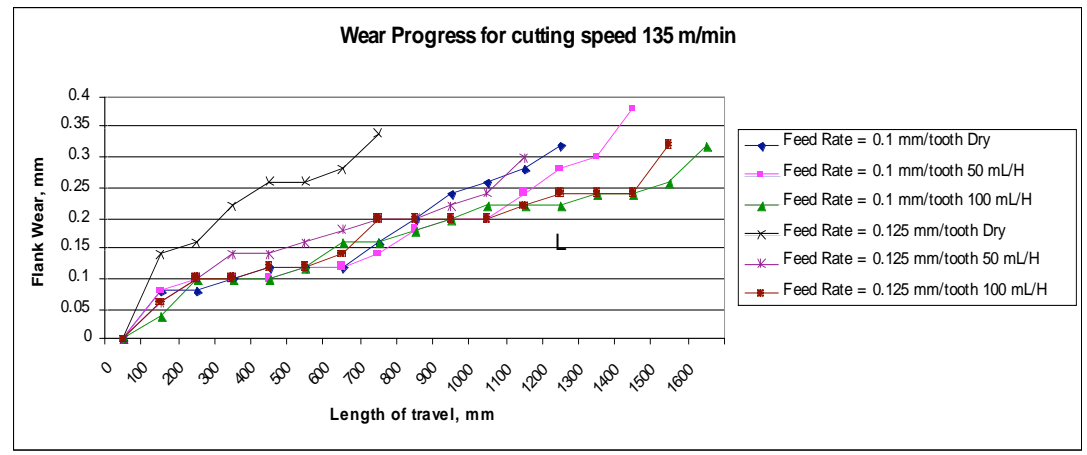

(b)

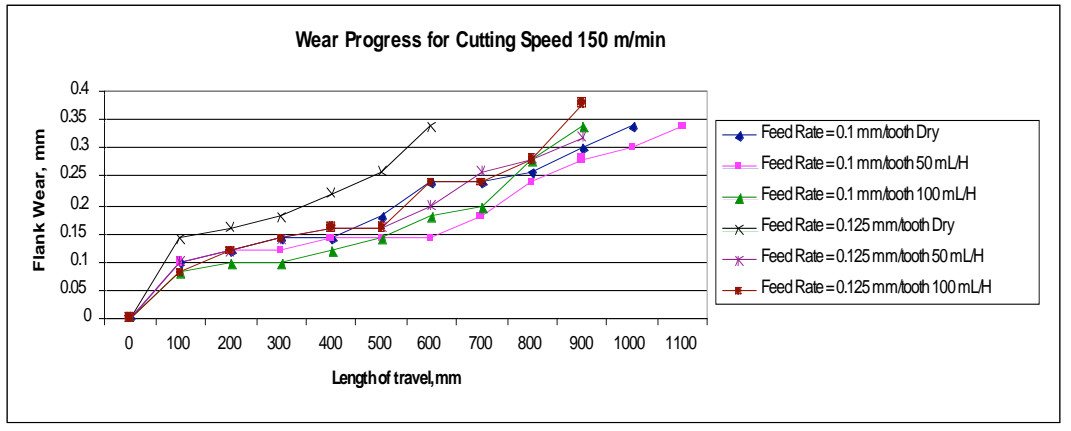

(c)

Fig. (5). Wear progress by different cutting speed (a) $120 \mathrm{~m} / \mathrm{min}$ (b) $135 \mathrm{~m} / \mathrm{min}$ (c) $150 \mathrm{~m} / \mathrm{min}$.

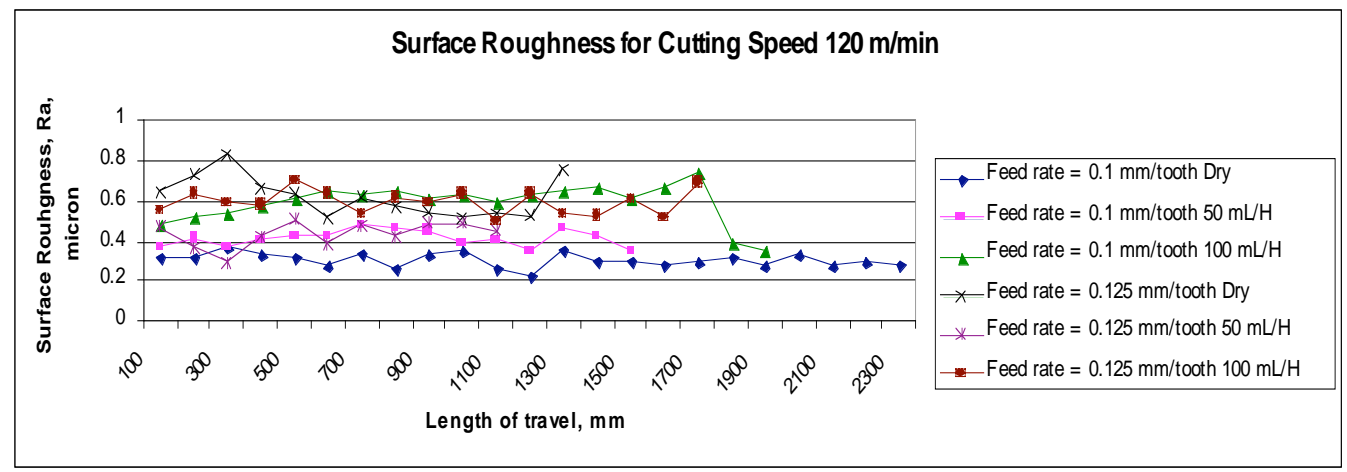

(a) $120 \mathrm{~m} / \mathrm{min}$

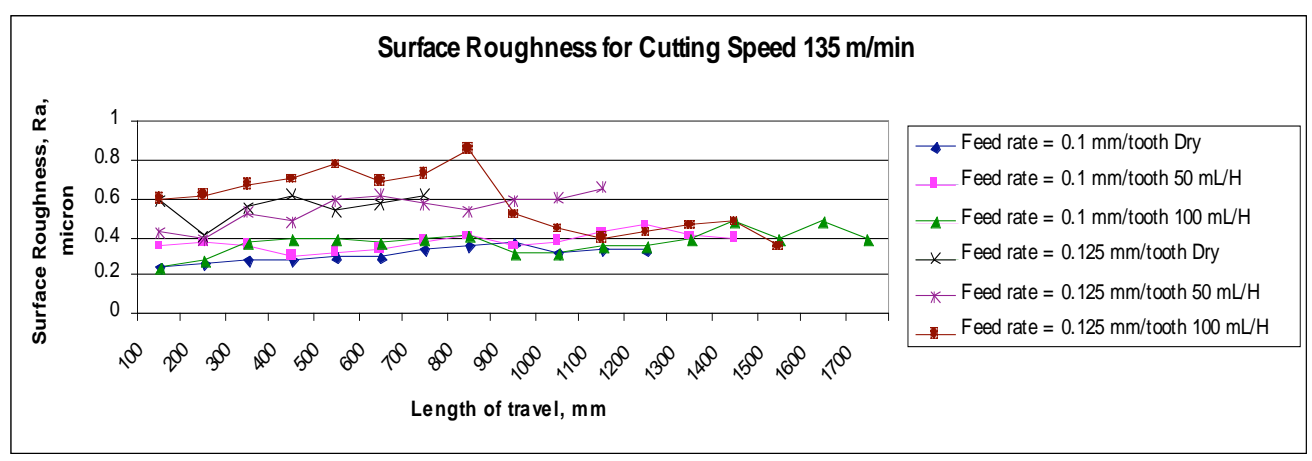

(b) $135 \mathrm{~m} / \mathrm{min}$ 
Fig. (6). contd....

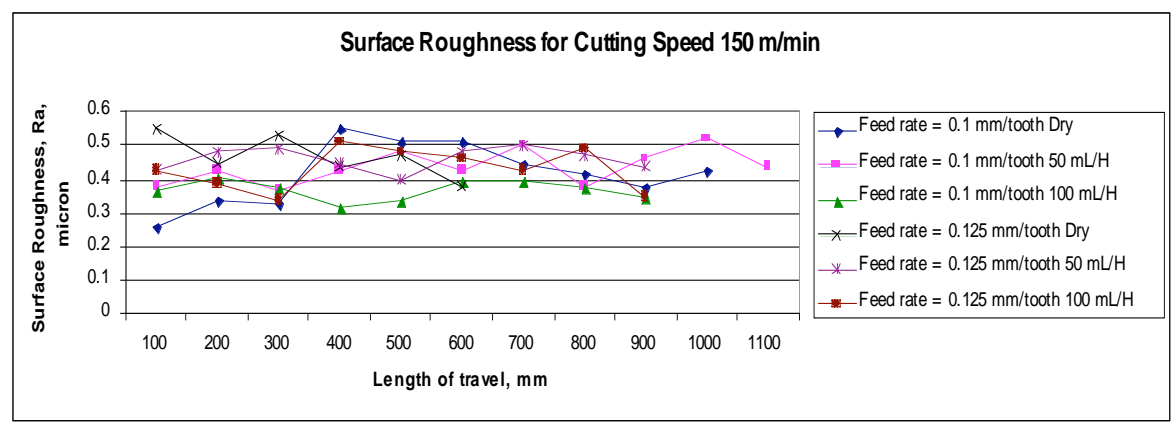

(c) $150 \mathrm{~m} / \mathrm{min}$

Fig. (6). Variation of surface roughness against length of travel for different cutting speeds.

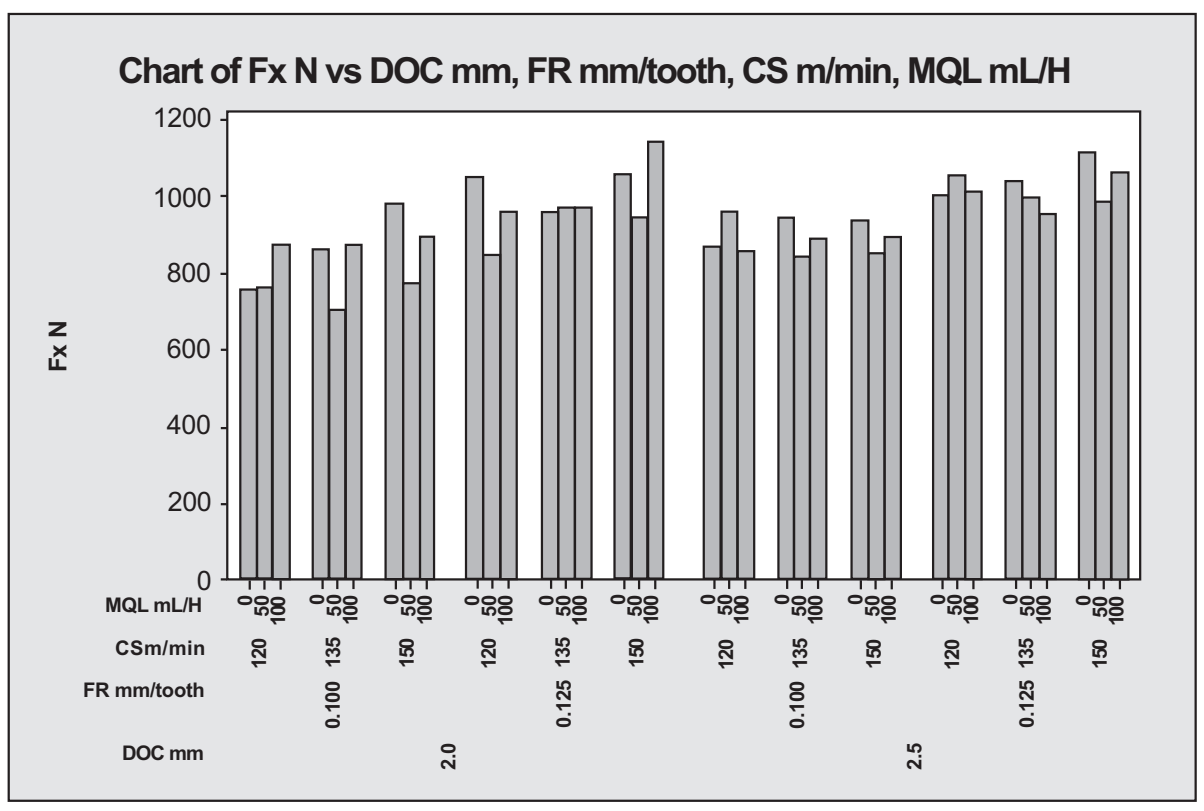

(a)

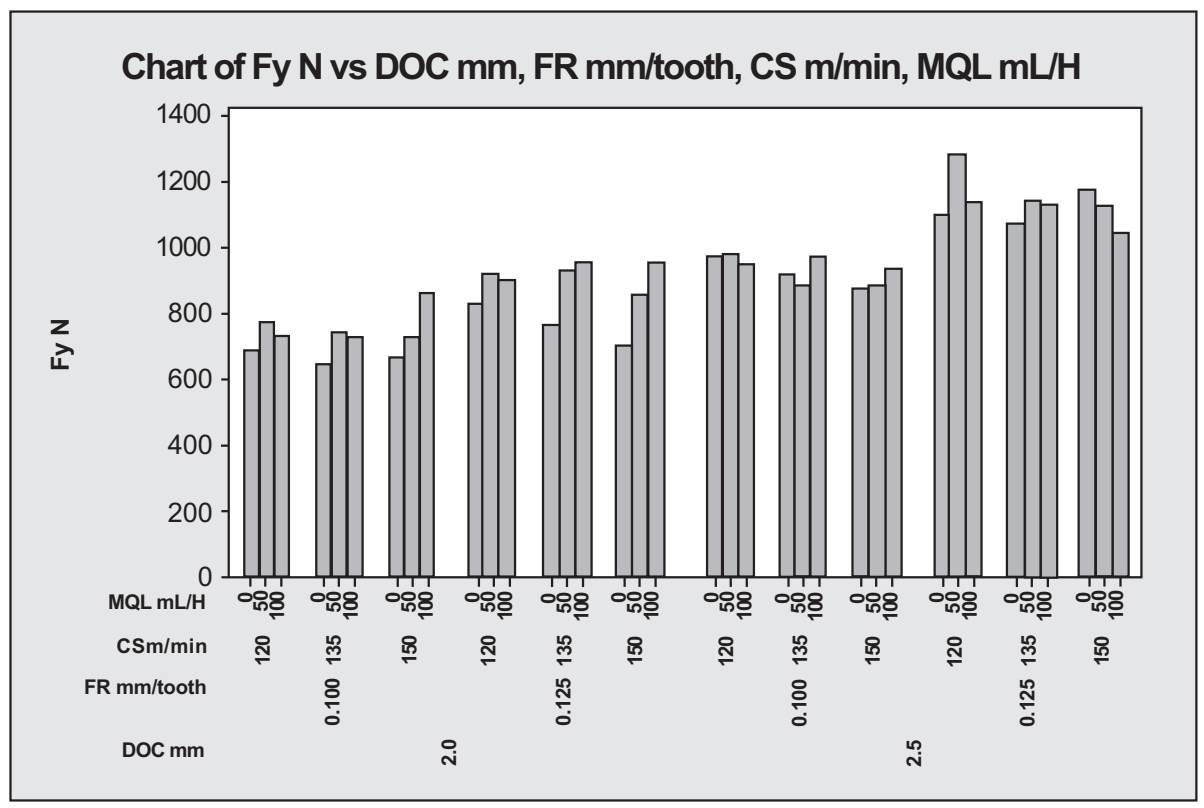

(b) 


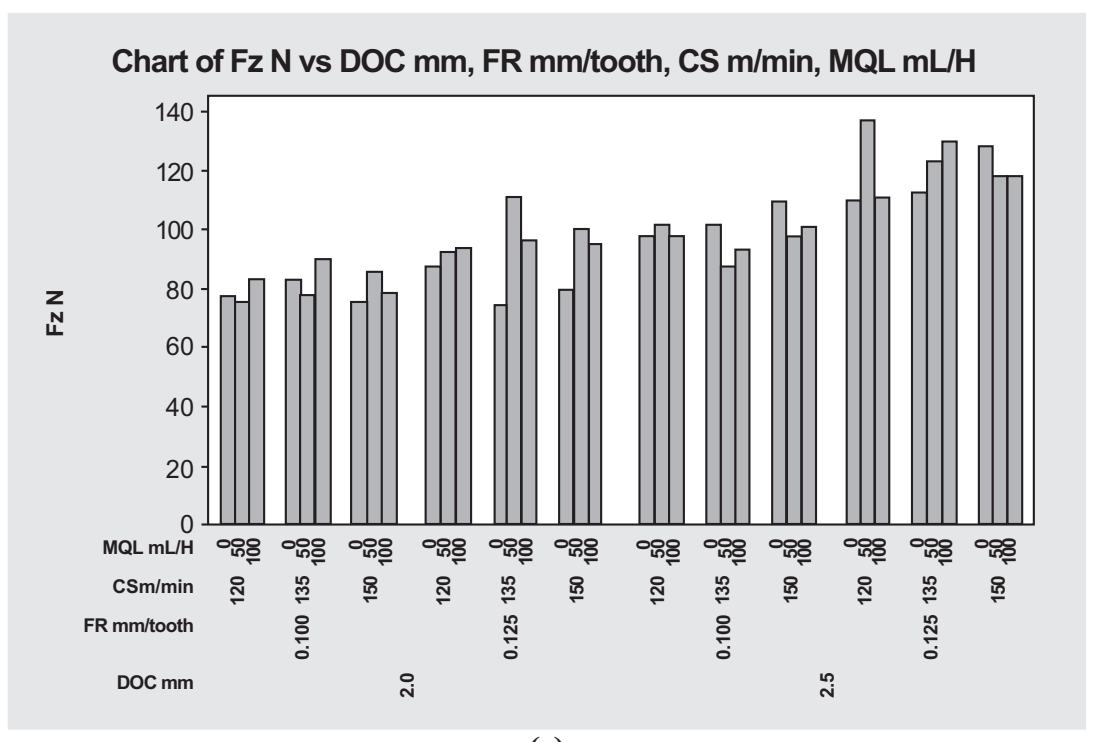

Fig. (7). contd....

(c)

Fig. (7). Histogram of cutting force vs MQL, cutting speed, feed rate and depth of cut (a) cutting force on X-axis (direction of feed) (b) Yaxis (perpendicular to feed) (c) Z-axis (axial).

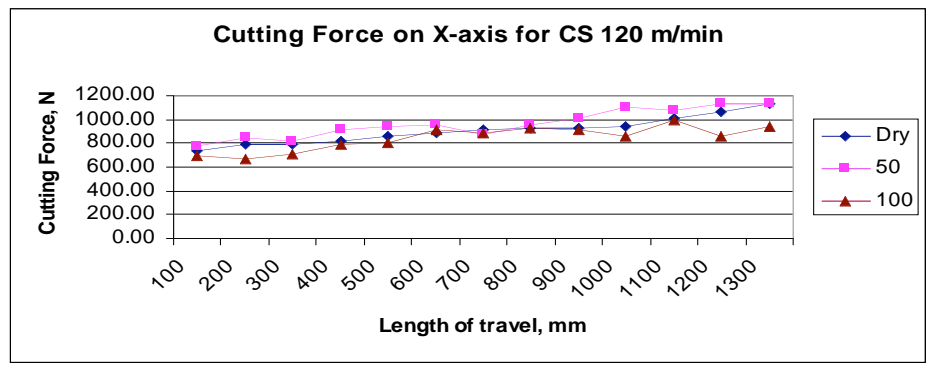

(a)

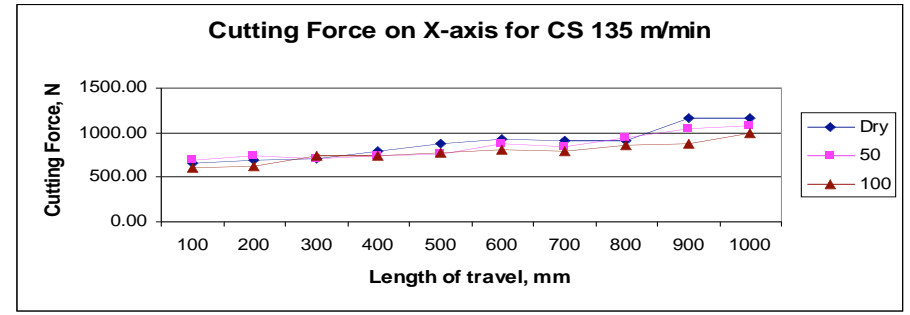

(b)

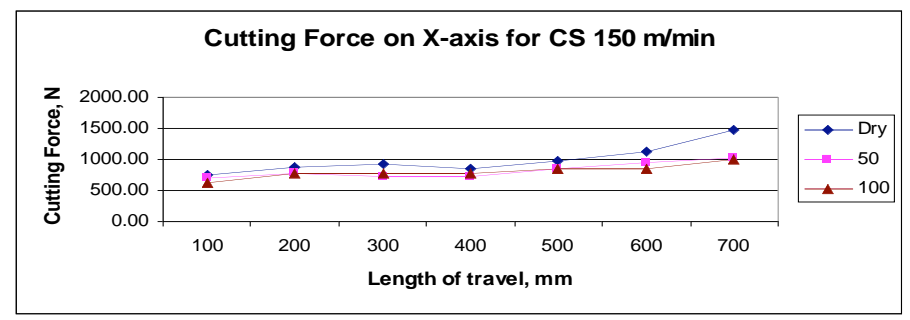

(c)

Fig. (8). Variation of cutting force (X-axis) vs length of travel at feed rate of $0.1 \mathrm{~mm} /$ tooth and depth of cut $2 \mathrm{~mm}$ (a) cutting speed 120 $\mathrm{m} / \mathrm{min}$ (b) cutting speed $135 \mathrm{~m} / \mathrm{min}$ (c) cutting speed $150 \mathrm{~m} / \mathrm{min}$.

cutting force. More energy is required to remove higher volume at shorter time.

No-linear correlation between cutting force and MQL might exist due to irregular pattern on the histogram when
MQL varied. Effect of cutting speed on cutting force seems to be not so significant. This is due to the small variation of cutting speed that was used in this experiment. Bigger variation of cutting speed should be used in order to study the effect of cutting speed on cutting force. 


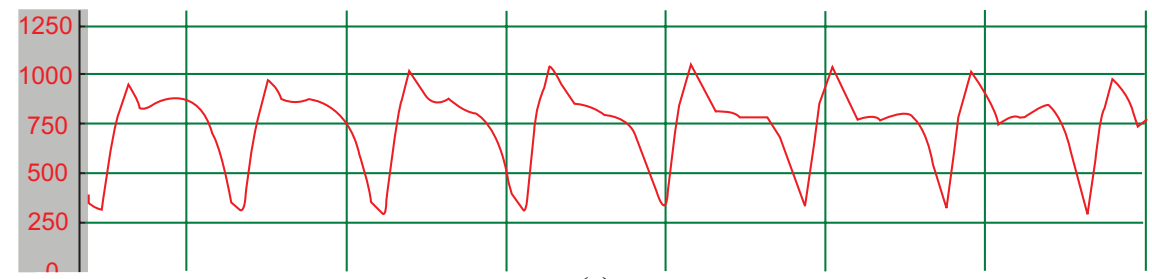

(a)

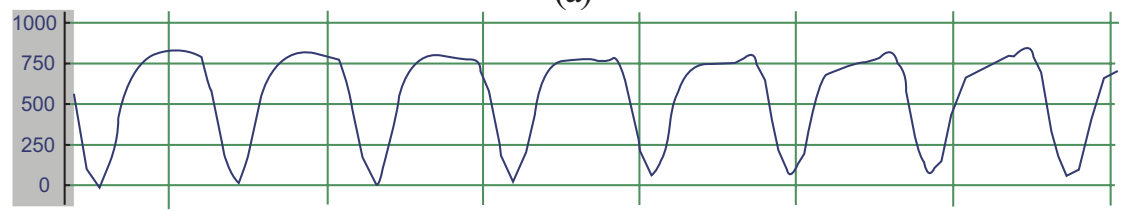

(b)

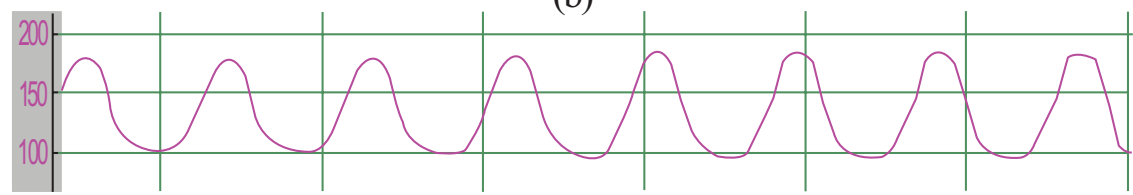

(c)

Fig. (9). Typical form of cutting force recorded in the experiment, cutting force (a) on X-axis, (b) on Y-axis, (c) on Z- axis.

Graphs in Fig. (8) show the variation of cutting force obtained progressively during machining. Higher cutting force was obtained at the end of machining. At this stage, the flank wear reached $0.3 \mathrm{~mm}$. When the tool tip became dull, more contact area between tool tip and work piece was created. This resulted in bigger friction, and thus increased the cutting force. At this stage, effect of MQL seemed to be more significant. Dry condition exhibited in higher cutting force, while lower cutting force was obtained when MQL was applied.

Fig. (9) shows the typical form of cutting force recorded during the experiment. This cyclic form of data is due to the interrupted cutting process in milling operation. The period or the frequency depends on the rotational speed of the cutting tool. Single peck at every single cycle was observed, due to only one insert that was used in this experiment. One cutting process occurred in one rotation of the cutting tool.

\section{CONCLUSION}

From this experiment, we can conclude that:

At any cutting condition, the cutting speed is the dominant factor in controlling tool life.

The application of MQL is not always effective in term of tool life and surface roughness. MQL is only effective at certain cutting speeds. In this experiment MQL is most effective at cutting speed of $135 \mathrm{~m} / \mathrm{min}$ to get better tool life.

High value MQL is less effective at high cutting speed due to the difficulty of the larger particle to penetrate into the cutting zone. Higher pressure is needed to ensure that the mist particle can penetrate into the cutting zone, when higher cutting speed is applied.

Direct effect of cutting parameter on the surface roughness is not significant. Surface roughness is more dependent on the geometry of the cutting tool and the stability of the machine structure. However, effect of feed rate on surface roughness is more significant as compared to other cutting parameters.
Although the effect of MQL on tool life is not significant, MQL seems to be more effective when worn out tool is applied. More contact area between tool and work piece will give better lubrication effect.

\section{REFERENCES}

[1] E. O. Ezugwu, "Key improvements in the machining of difficult-tocut aerospace superalloys, "International Journal of Machine Tools and Manufacturer, pp. 1353-1367, 2005.

[2] Anonymous, "Machining Titanium and its alloys," <http:www/superalloys.com/Machining_titaniumhtm>, accessed 4/3/2006.

[3] E. O. Ezugwu, J. Booney, and Y. Yamane, "An overview of the machinability of earoengine alloys, "Journal of Materials Processing Technology, pp. 233-253, 2003.

[4] Anonymous, "Titanium," <http://en.wikipedia.org/wiki/Titanium>, accesssed 3/16/2006

[5] N. R. Dhar, M. W. Islam, S. Islam, and M. A. H. Mithu, "The influence of minimum quantity of lubrication (MQL) on cutting temperature, chip and dimensional accuracy in turning AISI-1040 steel, "Journal of Materials Processing Technology, pp. 93-99, 2006.

[6] N. R. Dhar, M. T. Ahmed, and S. Islam, "An experimental investigation on effect of minimum quantity lubrication in machining AISI 1040 steel, "International Journal of Machine Tools and Manufacturer, pp. 748-753, 2007.

[7] C. H. Che Haron, "Tool life and surface integrity in turning titanium alloy, "Journal of Materials Processing Technology, pp. 231237, 2001.

[8] S. Cardoso Santos, W. F. Sales, F. J. da Silva, S. D. Franco, and M. B. da Silva, "Tribological characterization of PVD coatings for cutting tools, "International Journal of Surface and Coating Technology, pp. 141-148, 2003.

[9] M. Sokovic, J. Kopac, L. A. Dobrzanski, and M. Adamiak, "Wear of PVD-coated solid carbide end mills in dry high-speed cutting, " Journal of Materials Processing Technology, pp. 422-426, 2004.

[10] M. Rahman, A. Senthil Kumar, and M.U. Salam, "Experimental evaluation on the effect of minimal quantities of lubricant in milling, "International Journal of Machine Tools and Manufacturer, pp. 539-547, 2002.

[11] M. Rahman, Z. G. Wang, and Y. S. Wong, "High speed machining of Titanium alloys, "presented at International Conference on Manufacturing Science and Technology, Malaysia, 2006.

[12] N. R. Dhar, M. Kamruzzaman, and M. Ahmed, "Effect of minimum quantity lubrication (MQL) on tool wear and surface rough- 
ness in turning AISI-4340 steel,"Journal of Materials Processing Technology, pp. 299-304, 2006.

[13] L. N. Lopez de Lacalle, C. Angulo, A. Lamikiz, and J. A. Sanchez, "Experimental and numerical investigation of the effect of spray cutting fluids in high speed milling, "Journal of Materials Processing Technology, 2005.
[14] M. Rahman, Z. G. Wang, and Y. S. Wong, "High speed machining of Titanium alloys, "presented at International Conference on Manufacturing Science and Technology, Malaysia, 2006.

[15] A. Bhattacharyya, Metal Cutting - Theory and practice. India, 1984.

Received: February 14, 2008

Revised: July 14, 2008

Accepted: July 22, 2008

(C) Yasir et al.; Licensee Bentham Open.

This is an open access article licensed under the terms of the Creative Commons Attribution Non-Commercial License (http://creativecommons.org/licenses/by-nc/3.0/) which permits unrestricted, non-commercial use, distribution and reproduction in any medium, provided the work is properly cited. 